\title{
Drug-Drug Interactions with Direct Oral Anticoagulants
}

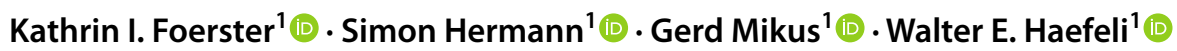

Published online: 11 March 2020

(c) The Author(s) 2020, Corrected Publication 2020

\begin{abstract}
A large body of evidence suggests that not only direct anticoagulant effects but also major bleeding events and stroke prevention depend on plasma concentrations of direct oral anticoagulants (DOACs). Concomitant drugs that cause drug-drug interactions (DDIs) alter DOAC exposure by increasing or decreasing DOAC bioavailability and/or clearance; hence, they might affect the efficacy and safety of DOAC therapy. Patients with renal impairment already receive smaller DOAC maintenance doses because avoidance of elevated DOAC exposure might prevent serious bleeding events. For other causes of increased exposure such as DDIs, management is often less well-defined. Considering that DOAC patients are often older and have multiple co-morbidities, polypharmacy is highly prevalent. However, the effect of multiple drugs on DOAC exposure, and especially the impact of DDIs when concurring with drug-disease interactions as observed in renal impairment, has not been thoroughly elucidated. In order to provide effective and safe anticoagulation with DOACs, understanding the mechanisms and magnitude of DDIs appears relevant. Instead of avoiding drug combinations with DOACs, more DDI trials should be conducted and new strategies such as dose adjustments based on therapeutic drug monitoring should be investigated. However, dose adjustments based on concentration measurements cannot currently be recommended because evidence-based data are missing.
\end{abstract}

\section{Importance of Direct Oral Anticoagulant (DOAC) Exposure for Beneficial and Adverse Effects}

Direct oral anticoagulants (DOACs) competitively, directly, selectively, and reversibly inhibit the coagulation factors thrombin (dabigatran) or factor Xa (FXa; apixaban, betrixaban, edoxaban, and rivaroxaban) [1-5]. Therefore, DOAC action is concentration dependent and DOAC coagulation effects closely follow the plasma concentration-time profile of the respective anticoagulant [6-9]. As a consequence, the activity of inhibited blood coagulation factors will be restored as soon as DOACs are eliminated or displaced from their target, which is already successfully used with antidotes such as andexanet alfa and idarucizumab [10, 11]. Conversely, increasing exposure by inhibiting DOAC clearance will immediately enhance anticoagulation effects, similar to dose escalation. In agreement with this concept, the

Gerd Mikus

gerd.mikus@med.uni-heidelberg.de

1 Department of Clinical Pharmacology and Pharmacoepidemiology, Heidelberg University Hospital, Im Neuenheimer Feld 410, 69120 Heidelberg, Germany likelihood of both preventing ischemic strokes and experiencing meaningful clinical adverse events of DOAC therapy (i.e., major bleeding) depends on DOAC exposure [12-14]. However, DOAC exposures appear to affect relevant clinical endpoints less closely and clearly than they do coagulation. Large efficacy trials could prove that DOACs were safe and effective without regular coagulation monitoring and subsequent dose adjustment despite large inter-individual pharmacokinetic variability (i.e. the cited trials show this) [15-18].

In two of the pivotal trials, DOAC minimum (trough) concentration $\left(C_{\min }\right)$ monitoring was performed and stroke prevention (efficacy) and bleeding events (toxicity)but not intracranial bleeding-increased with increasing DOAC concentrations in plasma $[12,13]$. For example, a $100 \%$ increase of dabigatran concentration reduced the risk of stroke by approximately $15 \%$ but increased the risk of major bleeding by $50 \%$ [12]. In this analysis, no major differences in the predictive values of $C_{\min }$ and maximum (peak) concentrations $\left(C_{\max }\right)$ were observed. Similar relationships with $C_{\min }$ were observed in one of the pivotal edoxaban trials [ENGAGE AF-TIMI 48 (Effective aNticoaGulation with factor XA next GEneration in Atrial Fibrillation-Thrombolysis In Myocardial Infarction study 48)] [13]. Only trough samples were collected, which was justified by another trial 


\section{Key Points}

Direct oral anticoagulant (DOAC) plasma concentrations are closely associated with the efficacy and safety of DOAC therapy and concomitant drugs can increase or decrease DOAC exposure by changing DOAC bioavailability and/or clearance.

Drugs that alter DOAC exposure or increase patients' bleeding risk are frequently prescribed because DOAC patients are often older and multimorbid and, hence, concomitantly administered many drugs (polypharmacy), or present with renal impairment and an interacting drug. Current guidelines often do not include careful and practical management of drug-drug interactions (DDIs) in these complex situations because they have often not been studied.

Instead of avoiding drug combinations with DOACwhich can be impossible-more DDI trials should be conducted and new strategies such as dose adjustments based on monitoring should be investigated.

However, DOAC dose adjustments based on concentration measurements cannot be recommended because evidence-based data are currently missing.

suggesting a relevant relationship between edoxaban $C_{\min }$ and bleeding events [19]. Despite receiving the same dose [and having similar areas under the concentration-time curve (AUCs)], the likelihood of severe bleeding was significantly increased in patients who had higher $C_{\min }$ and lower $C_{\text {max }}$ values because of different dosing regimens (edoxaban $30 \mathrm{mg}$ twice daily vs. edoxaban $60 \mathrm{mg}$ once daily) [19]. In contrast, major and non-major bleeding episodes in patients taking rivaroxaban were more frequent in those who had a higher $C_{\max }$ or AUC, whereas bleeding events during apixaban correlated better with AUC or $C_{\text {min }}$ than with $C_{\max }[14$, $20,21]$. Although evidence suggests that $C_{\min }$ is the value that best predicts edoxaban toxicity, trials investigating this relationship are rare. It seems that not only average exposure (AUC) but also the shape of the concentration-time curve (i.e., $C_{\max }$ and $C_{\min }$ ) might modulate risk, but it is still unknown which pharmacokinetic parameters (AUC, $C_{\min }$, or $C_{\text {max }}$ ) matter and whether this is similar for all DOACs and all clinical endpoints.

In conclusion, a large body of evidence suggests that not only direct anticoagulant effects but also major bleeding events and stroke prevention depend on plasma concentrations of DOACs. Even though intracranial bleeding-albeit occurring rarely under DOAC therapy_might not be prevented by monitoring plasma concentrations [13], the existing data indicate that serious bleeding events under DOAC therapy might be preventable by avoiding elevated DOAC concentrations in plasma. As a consequence, to minimize potential bleeding risks, approved DOAC maintenance doses are smaller for patients with elevated DOAC concentrations, such as patients with renal impairment. For other causes of increased exposure such as drug-drug interactions (DDIs), management is often less well-defined [22-25]. Considering that patients with non-valvular atrial fibrillation (a common indication for DOACs) are often older and have multiple comorbidities, which require the use of drugs [26], polypharmacy is highly prevalent in these patients (40-77\%) [27-30]. Many typical co-medications can interact with DOACs and modify their exposure. However, the effect of multiple drugs on DOAC exposure, and especially the impact of DDIs when concurring with drug-disease interactions as observed in renal impairment, has not been thoroughly elucidated [31]. In order to provide effective and safe anticoagulation with DOACs, understanding the magnitude and mechanisms of DDIs appears relevant. This review illustrates the impact of perpetrator drugs on DOAC exposure with a special focus on the combined risk of multiple drug therapies and multiple conditions on DOAC therapy.

\section{Basics of DOAC Pharmacokinetics}

The factors that influence plasma concentrations of orally administered drugs [steady-state concentration $\left(C_{\mathrm{ss}}\right)$ ] in adherent patients are shown in Eq. 1.

$C_{\mathrm{ss}}=\frac{F \times D}{\mathrm{CL} \times \tau}$.

At a given dose $(D)$ and dosing interval $(\tau)$, DOAC $C_{\mathrm{ss}}$ is determined by oral bioavailability $(F)$ and clearance (CL). Both variables depend on the activity of drug transporters such as P-glycoprotein (P-gp) and breast cancer resistance protein (BCRP) or drug-metabolizing enzymes such as cytochrome P450 (CYP) isozymes or carboxylesterases (CES), whose activities are often modified by co-medication or patient conditions such as genetic polymorphisms. However, because nature and proportional contribution of absorption and clearance mechanisms of DOACs are diverse, individual DOAC victim properties are also heterogeneous and neither DDIs nor drug-disease interactions are class phenomena.

\subsection{Apixaban}

Apixaban is well-soluble at different gastric conditions but its oral bioavailability is only $49 \%$ [32]. Probably more than P-gp, BCRP limits the oral bioavailability of apixaban [33-37]. A proportion of apixaban is cleared by CYP3A4 
( $\sim 15 \%$ of an oral dose) with minor contribution of other isozymes (e.g., CYP1A2 and CYP2J2) ( 6\% of an oral dose) (Fig. 1) [38]. Apixaban's metabolites are pharmacologically inactive and some are further metabolized by sulfotransferase (SULT) 1A1 [39]. Apixaban is also eliminated unchanged; renal clearance of unchanged apixaban accounts for approximately $27 \%$ [32], but also biliary $(<1 \%)$ [38] and direct secretion into feces (based on animal studies) have been proposed as clearance pathways of apixaban (Fig. 1) $[40,41]$. In general, the different apixaban clearance pathways are well-balanced, which prevents patients from clinically significant apixaban exposure changes if only a single pathway is disturbed. For example, even severe renal impairment (creatinine clearance of $15 \mathrm{~mL} / \mathrm{min}$ ) only increased the apixaban AUC by 44\% [42]. However, DDIs with apixaban can modulate both apixaban bioavailability and clearance and more than one clearance pathway simultaneously. For example, the strong CYP3A4, BCRP, and P-gp inhibitor ketoconazole doubled the apixaban AUC, probably because it concurrently increased apixaban bioavailability and inhibited most of its oxidative metabolism [43]. Strong inducers of CYP isozymes, BCRP, and P-gp such as rifampicin (rifampin) will halve the apixaban AUC, probably because they further decrease the absorbed fraction [32]. Currently reported DDIs with apixaban are depicted in Fig. 2.

\subsection{Betrixaban}

Oral bioavailability of betrixaban accounts for approximately $34 \%$, which can be further reduced by fatty food even when taken hours before betrixaban $[2,44]$. A higher betrixaban dose should therefore be taken with food. The major clearance pathway of betrixaban from the body is hepatic elimination mainly by biliary secretion $(\sim 80 \%)$; renal elimination is less relevant (approximately 20\%) (Fig. 1) [2]. Betrixaban metabolism is largely independent from CYP isozymes $(<1 \%)$ but betrixaban is subject to hydrolysis (Fig. 1) [2]. Betrixaban as a P-gp substrate is susceptible to P-gp-related drug interactions [45]. Co-administration of potent P-gp inhibitors can influence the bioavailability and clearance of betrixaban. For example, the P-gp inhibitor verapamil increased the betrixaban $C_{\max } 4.7$-fold and its AUC 3-fold [2]. However, the expected effects of potent P-gp inducers (e.g., rifampicin) on betrixaban exposure have not been examined yet. Renal impairment can also substantially increase betrixaban exposure [46]. Currently known DDIs with betrixaban are depicted in Fig. 3 .

\subsection{Dabigatran}

The thrombin inhibitor dabigatran is administered as a prodrug (dabigatran etexilate) because active dabigatran is a poorly available hydrophilic zwitterion [3]. Other than dabigatran, its prodrug is a P-gp substrate [33] and rather insoluble at $\mathrm{pH}$ values of 3-7.5 [47], resulting in an oral bioavailability of only 7.5\% [48]. Polymorphic hepatic CES 1 , intestinal CES 2, and also unspecific hydrolysis convert dabigatran etexilate into dabigatran $[49,50]$. Unchanged renal elimination is the predominant elimination pathway of dabigatran ( 77\%) (Fig. 1) [48]. Dabigatran has negligible metabolism overall with $<10 \%$ of dabigatran being oxidized or conjugated with glucuronic acid by UDP-glucuronosyltransferase (UGT) 1A9, 2B7, and especially 2B15 (Fig. 1) $[48,51]$ to active acylglucuronides [51]. Therefore, DDIs predominantly affect bioavailability and P-gp inhibitors such as verapamil can reduce the intestinal first-pass elimination and thus increase absorption [52]. With the addition of tartaric acid to the formulation, drugs such as proton pump inhibitors that alter gastric $\mathrm{pH}$ values no longer cause relevant changes in dabigatran bioavailability [53]. Apart from DDIs, which can double dabigatran bioavailability and thus its exposure, renal impairment can even more profoundly increase dabigatran exposure, resulting in an exposure increase of $50 \%$ (mild renal impairment) to $500 \%$ (severe renal impairment) [54]. The currently known DDIs with dabigatran are depicted in Fig. 4.

\subsection{Edoxaban}

Only approximately $62 \%$ of an oral edoxaban dose is bioavailable [55], partly because of P-gp (and probably BCRP)mediated efflux $[33,56]$. Edoxaban is primarily eliminated unchanged by the kidneys (50\%) but CES 1 and CYP3A4/5 contribute to its phase I metabolism $(<10 \%)$ (Fig. 1) [57], resulting in active but scarce metabolites [8] $(<10 \%$ of edoxaban AUC) [57] and therefore without clinical significance. Edoxaban absorption and clearance depend on P-gp efflux. In the kidneys, edoxaban is filtrated as well as actively secreted by P-gp (and possibly further transporters) [56]. Direct excretion of unchanged edoxaban into bile and intestine has been observed in rats and, thus, been proposed as an additional potential clearance pathway also in humans [56]. Therefore, P-gp inhibition by co-medication risks elevated edoxaban exposure because it increases edoxaban bioavailability and decreases edoxaban clearance. This has been demonstrated in a DDI trial investigating the effect of the P-gp inhibitor quinidine on intravenously and orally administered edoxaban [58], which reported increased bioavailability and decreased clearance with a similar contribution to an edoxaban AUC increase [58]. Conversely, P-gp inducers such as rifampicin decreased edoxaban exposure by $34 \%$ without affecting the $C_{\max }$, which suggests that P-gp inducers more likely decrease clearance than affect edoxaban bioavailability [59]. Further DDIs with edoxaban are depicted in Fig. 5. 


\section{Apixaban (p.o.)}

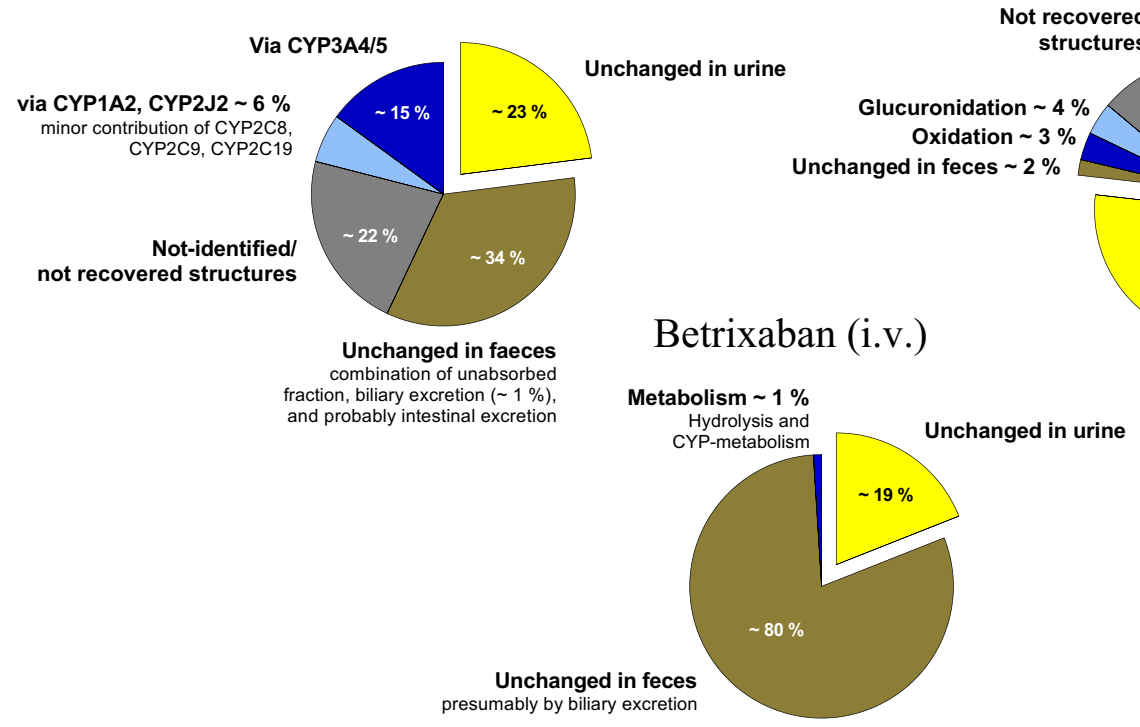

Dabigatran (i.v.)

recovered

ctures

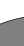

$\%$

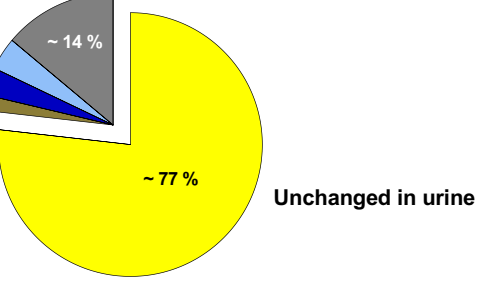

Unchanged in urine

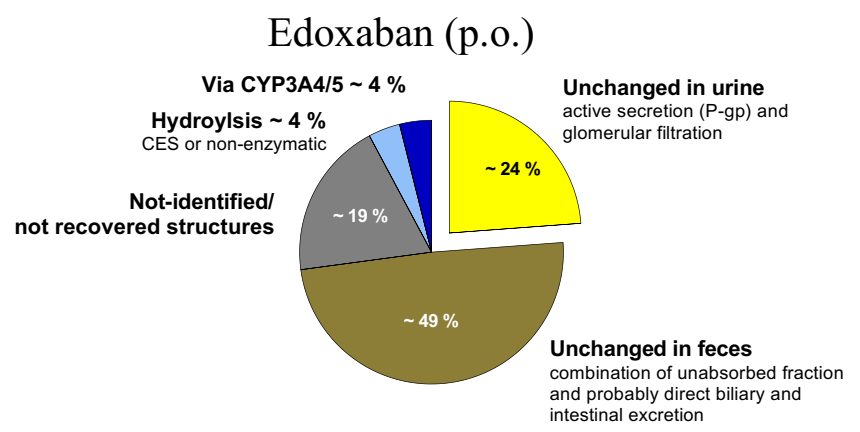

Edoxaban (p.o.)

Via CYP3A4/5 $4 \%$

Fig. 1 Primary direct oral anticoagulant (DOAC) clearance/elimination pathways. Data were extracted from per oral (po; apixaban, edoxaban, and rivaroxaban) and intravenous (iv; betrixaban and dabigatran) mass balance studies [2, 38, 48, 57]. The rivaroxa-

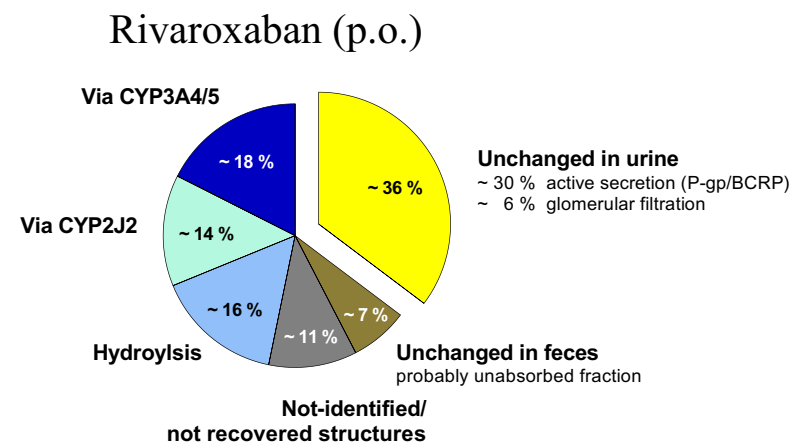

ban pie chart is a modification from Mueck and co-workers [63]. $B C R P$ breast cancer resistance protein, $C E S$ carboxylesterase, $C Y P$ cytochrome $\mathrm{P} 450, P$-g $p$ P-glycoprotein

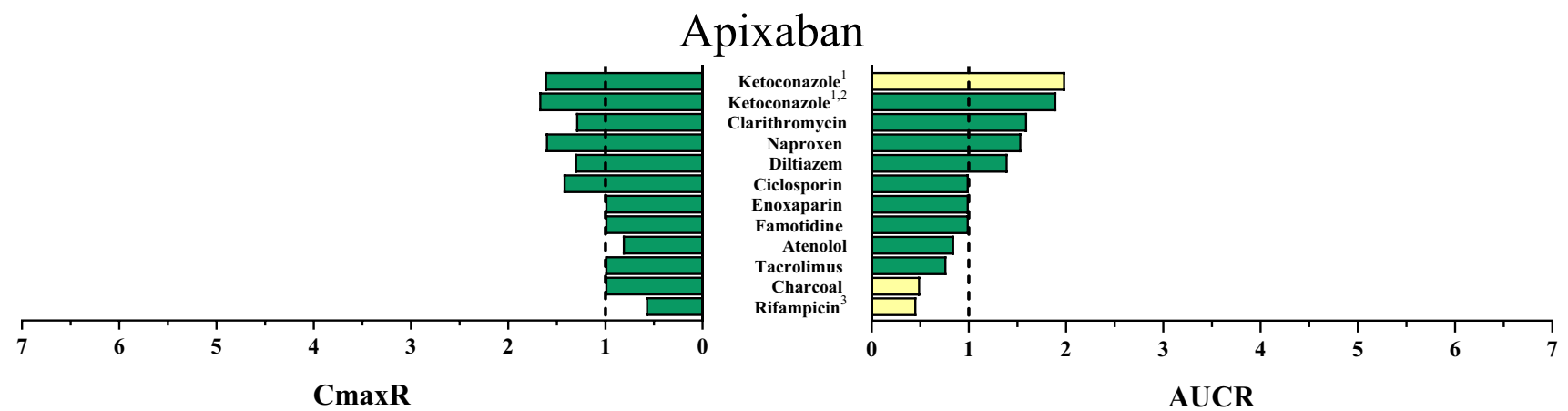

Fig. 2 Area under the concentration-time curve ratios (AUCR) and maximum (peak) concentration ratios $\left(C_{\max } \mathrm{R}\right)$ of apixaban with and without concomitantly taken drugs. Results of drug-drug interaction trials that have been conducted and published up to January 2020 are depicted $[22,32,36,40,43,85,98-101]$. A ratio equals 1 if the co- administered drug statistically insignificantly influenced direct oral anticoagulant (DOAC) pharmacokinetics. Green bars: AUCR and $C_{\max } \mathrm{R}>0.5$ and $<2$. Yellow bars: AUCR and $C_{\max } \mathrm{R} \leq 0.5$ and $\geq 2$. ${ }^{1}$ Ketoconazole $400 \mathrm{mg}$ investigated. ${ }^{2} \mathrm{DOAC}$ microdoses administered. ${ }^{3}$ Rifampicin was given repeatedly 


\section{Betrixaban}

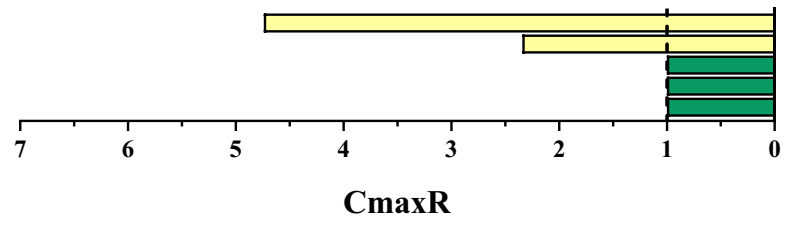

Fig. 3 Area under the concentration-time curve ratios (AUCR) and maximum (peak) concentration ratios $\left(C_{\max } \mathrm{R}\right)$ of betrixaban with and without concomitantly taken drugs. Results of drug-drug interaction trials that have been conducted and published up to January 2020 are depicted [2]. A ratio equals 1 if the co-administered drug statistically

\subsection{Rivaroxaban}

Rivaroxaban is the DOAC with the highest oral bioavailability $(\geq 80 \%)$ [60]. Rivaroxaban is also a P-gp and BCRP substrate and, in contrast to other DOACs, absorption of rivaroxaban doses exceeding $10 \mathrm{mg}$ requires food intake [33, 61] to avoid reductions of oral bioavailability to $66 \%$ [60, 62]. Similar to apixaban, relevant fractions of rivaroxaban insignificantly influenced direct oral anticoagulant pharmacokinetics. Green bars: AUCR and $C_{\max } \mathrm{R}>0.5$ and $<2$. Yellow bars: AUCR and $C_{\max } \mathrm{R} \leq 0.5$ and $\geq 2$. ${ }^{1}$ Verapamil provided in an extended-release formulation. ${ }^{2}$ Ketoconazole $200 \mathrm{mg}$ investigated. ${ }^{3}$ The antacid mixture was composed of aluminium hydroxide and magnesium hydroxide

are also metabolized by CYP3A4/5 $(\sim 18 \%)$, CYP2J2 $(\sim 14 \%)$, and non-enzymatic hydrolysis $(\sim 14 \%)$ (Fig. 1) [63]. The remaining $36 \%$ are eliminated unchanged by the kidney, with active secretion by P-gp and BCRP being the principal mechanism (only $6 \%$ of rivaroxaban is filtrated by glomeruli) (Fig. 1) [63, 64]. Thus, DDIs more likely alter rivaroxaban clearance than bioavailability. The largest effect that has been observed so far has been caused by

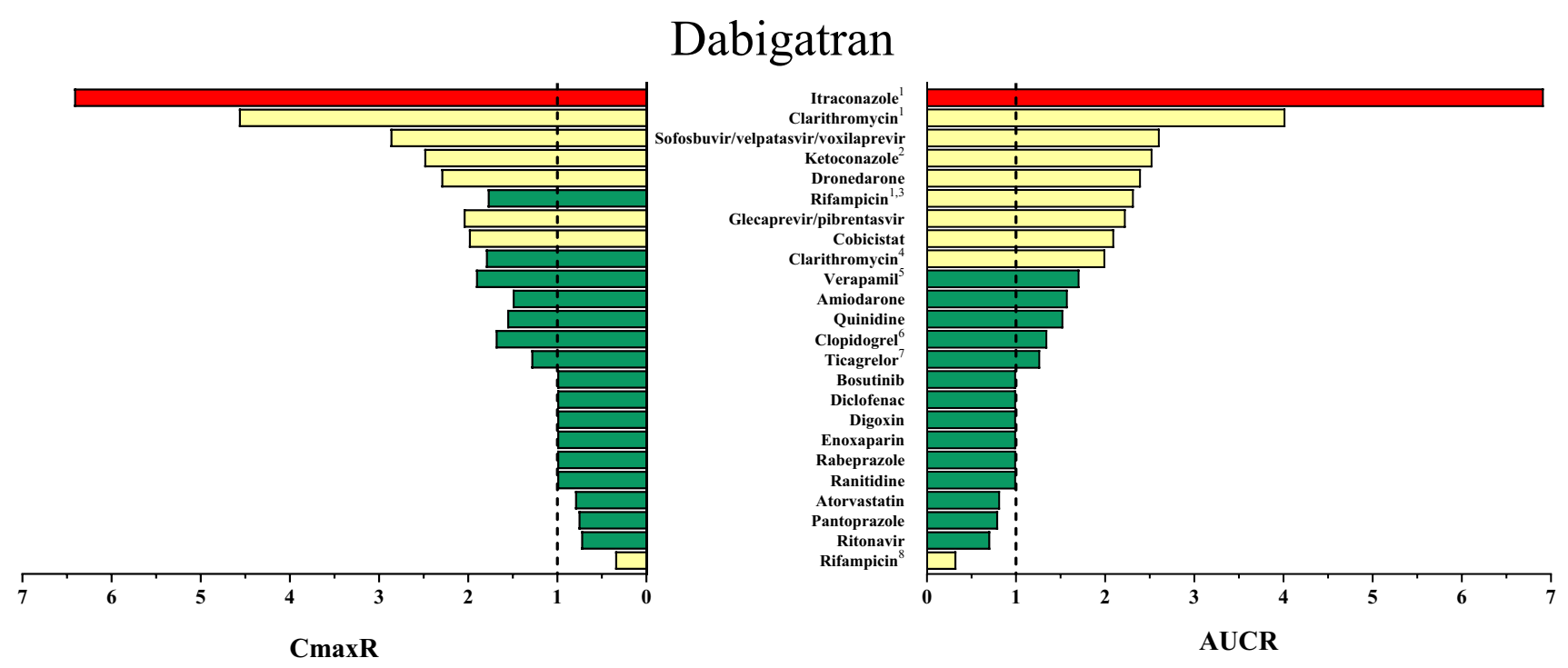

Fig. 4 Area under the concentration-time curve (AUC) ratios (AUCR) and maximum (peak) concentration $\left(C_{\max }\right)$ ratios $\left(C_{\max } \mathrm{R}\right)$ of dabigatran with and without concomitantly taken drugs. Results of drug-drug interaction (DDI) trials that have been conducted and published up to January 2020 are depicted [23, 52, 70, 71, 102-113]. A ratio equals 1 if the co-administered drug statistically insignificantly influenced direct oral anticoagulant (DOAC) pharmacokinetics. Green bars: AUCR and $C_{\max } \mathrm{R}>0.5$ and $<2$. Yellow bars: AUCR and $C_{\max } \mathrm{R} \leq 0.5$ and $\geq 2$. Red bars: AUCR and $C_{\max } \mathrm{R} \geq 5$. ${ }^{1} \mathrm{DOAC}$ microdoses administered. ${ }^{2}$ Ketoconazole $200 \mathrm{mg}$ investigated. ${ }^{3} \mathrm{~A}$ single dose of rifampicin was provided. ${ }^{4}$ The figure depicts the greatest effect of clarithromycin on dabigatran pharmacokinetics that has been reported. Results from DDI trials are ambiguous. Although the same dose of clarithromycin was administered, one trial did not observe any change in dabigatran exposure and the other reported a smaller AUCR than depicted (AUCR 1.49) [103, 105]. ${ }^{5}$ Verapamil was provided in an extended-release formulation. Immediate-release verapamil given $1 \mathrm{~h}$ before dabigatran etexilate had greater impact on dabigatran exposure. Immediate-release verapamil given $2 \mathrm{~h}$ after dabigatran etexilate did not alter dabigatran exposure to a relevant extent. ${ }^{6}$ Only loading doses of clopidogrel (300-600 mg) affected dabigatran exposure. ${ }^{7}$ Loading doses of ticagrelor $(180 \mathrm{mg})$ administered $2 \mathrm{~h}$ after dabigatran etexilate $110 \mathrm{mg}$ or maintenance doses of ticagrelor $(90 \mathrm{mg}$ ) administered concomitantly increased dabigatran exposure as depicted. Lower doses of dabigatran etexilate $(75 \mathrm{mg})$ were affected to a greater extent by ticagrelor (AUC 1.73-fold, $C_{\max }$ 1.95 -fold). ${ }^{8}$ Rifampicin was given repeatedly 
ketoconazole (rivaroxaban AUC increased more than 2.5fold), which likely resulted from a combined inhibition of hepatic CYP isozymes and renal efflux transporters [63]. Accordingly, the rivaroxaban AUC can increase with even mild renal impairment, as observed in healthy elderly who have a $41 \%$ higher rivaroxaban AUC [65, 66]. The impact of DDIs on rivaroxaban pharmacokinetics is depicted in Fig. 6.

\section{Drug-Drug Interactions Affecting DOAC Therapy}

As different uptake and clearance mechanisms of DOACs are quite heterogeneous (victim properties), individual perpetrator drugs will have grossly differing effects on the pharmacokinetics of individual DOACs. Because clearances are additive, the net observed change of an interacting comedication or condition depends on the extent of clearance impairment and on the overall contribution of this pathway to bioavailability and total clearance $[14,65,67,68]$. Commonly, DDI trials are designed to investigate worst-case scenarios and typically do not address the impact of co-morbidity. Thus, combinations of renal impairment with inhibition of CYP or P-gp, or inhibition of multiple pathways by drug combinations can significantly affect DOAC exposure. As an example, combined inhibition of CYP3A4 and P-gp will increase rivaroxaban exposures to a larger extent in patients with renal failure. The moderate CYP3A4 and P-gp inhibitor erythromycin increased rivaroxaban exposure in healthy individuals by $39 \%$ but resulted in a $76 \%$ increase in patients with mild renal impairment [69]. Although plasma exposure rose substantially, clear dosing instructions for this complex interaction are lacking. This contrasts with the instructions on the product label for patients on erythromycin alone, who do not require dose reductions, and patients with moderate renal impairment in whom rivaroxaban exposure increases $52 \%[25,65]$ and require a dose reduction. Obviously, dose selection cannot exclusively be based on DOAC pharmacokinetics because both benefits and harms as a result of anticoagulation can be modulated by co-morbidities and must be well-balanced. As an example, studies evaluating the actions of betrixaban in renal impairment revealed that betrixaban exposure roughly doubled in patients with creatinine clearance $<30 \mathrm{~mL} / \mathrm{min}$ and the bleeding risk substantially increased compared with the comparator enoxaparin [2]. If doses were adjusted to match betrixaban exposure of patients without renal impairment, bleeding risk was still elevated but efficacy was reduced, suggesting that therapeutic alternatives should be favored in patients with severe renal impairment.

Multi-medication can also significantly affect DOAC exposure as has been demonstrated with drug combinations approved for antiviral therapies. Glecaprevir plus pibrentasvir or sofosbuvir plus velpatasvir plus voxilaprevir (triple combination) increased dabigatran exposure more than twofold because P-gp inhibitors of different potencies are used simultaneously. As a consequence, the current advice is to interrupt dabigatran therapy [70, 71]. However, apart

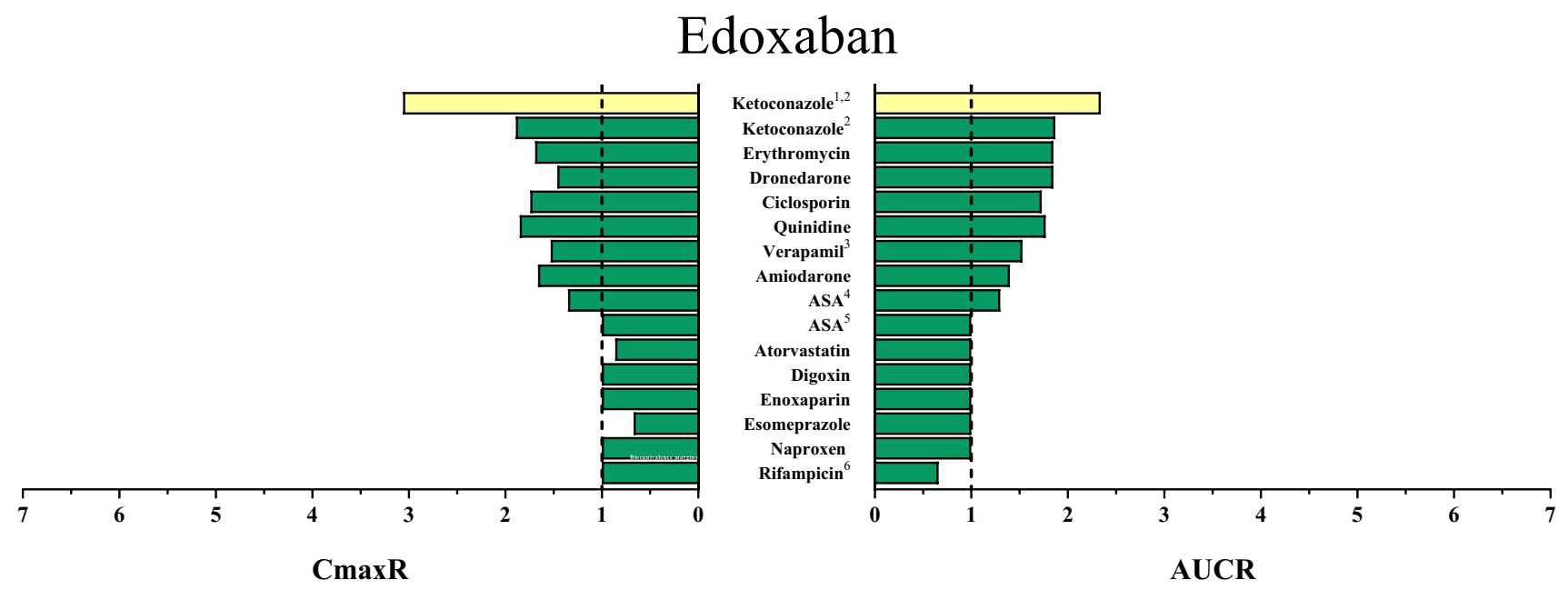

Fig. 5 Area under the concentration-time curve ratios (AUCR) and maximum (peak) concentration ratios $\left(C_{\max } \mathrm{R}\right)$ of edoxaban with and without concomitantly taken drugs. Results of drug-drug interaction trials that have been conducted and published up to January 2020 are depicted [59, 76, 84, 98, 114-117]. A ratio equals 1 if the co-administered drug statistically insignificantly influenced direct oral anticoag- ulant (DOAC) pharmacokinetics. Green bars: AUCR and $C_{\max } \mathrm{R}>0.5$ and $<2$. Yellow bars: AUCR and $C_{\max } \mathrm{R} \leq 0.5$ and $\geq 2$. Red bars: AUCR and $C_{\max } \mathrm{R} \geq 5$. ${ }^{1}$ DOAC microdoses administered. ${ }^{2}$ Ketoconazole $400 \mathrm{mg}$ investigated. ${ }^{3}$ Verapamil provided in an extended-release formulation. ${ }^{4}$ Acetylsalicylic acid (ASA) $325 \mathrm{mg} /$ day administered. ${ }^{5}$ ASA 100 mg/day administered. ${ }^{6}$ Rifampicin was given repeatedly 


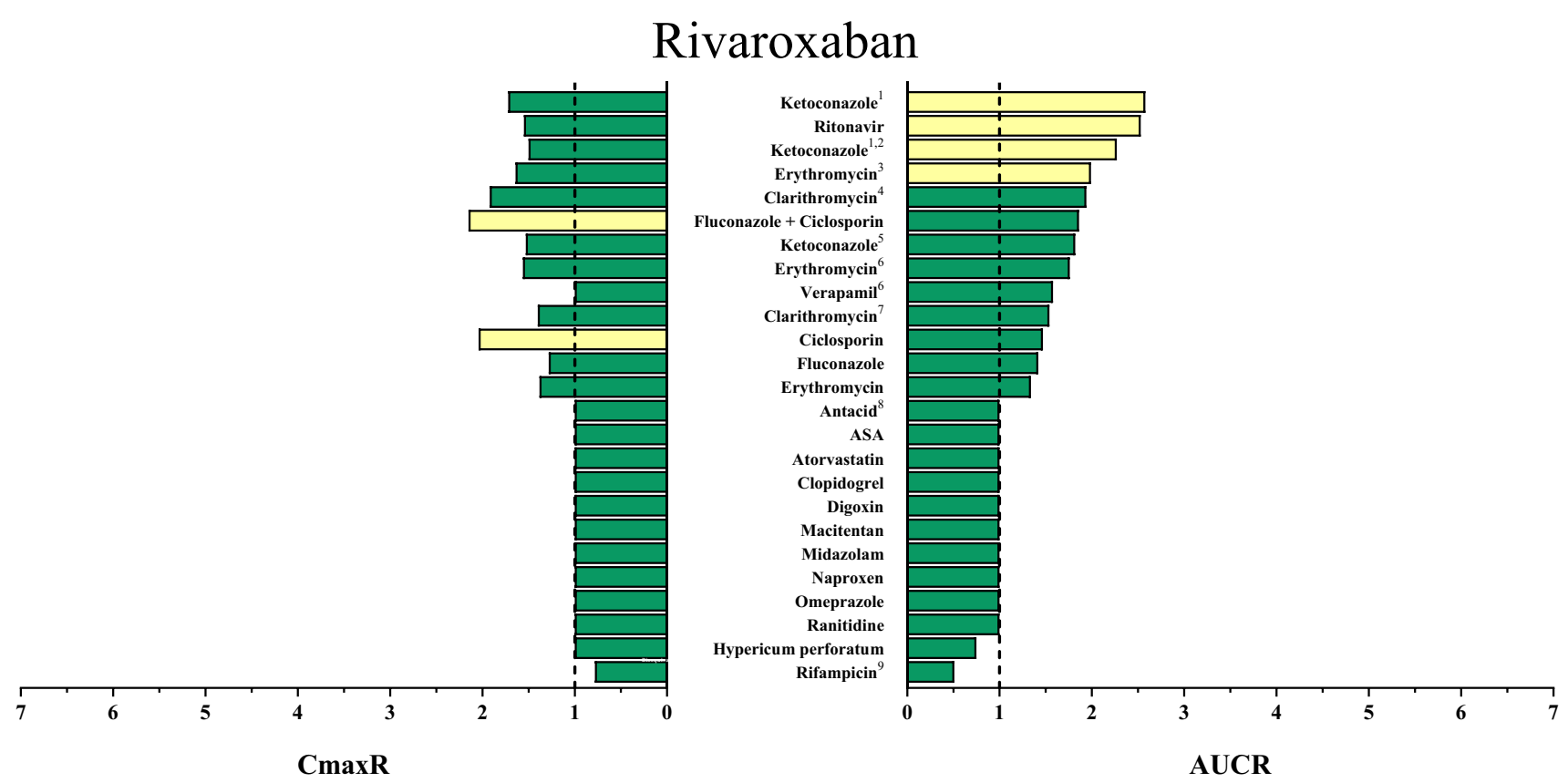

Fig. 6 Area under the concentration-time curve ratios (AUCR) and maximum (peak) concentration ratios $\left(C_{\max } \mathrm{R}\right)$ of rivaroxaban with and without concomitantly taken drugs. Results of drug-drug interaction trials that have been conducted and published up to January 2020 are depicted $[62,63,69,74,81-83,98,104,118-122]$. A ratio equals 1 if the co-administered drug statistically insignificantly influenced direct oral anticoagulant (DOAC) pharmacokinetics. Green bars: AUCR and $C_{\max } \mathrm{R}>0.5$ and $<2$. Yellow bars: AUCR and $C_{\max } \mathrm{R}$

from antiviral therapies, P-gp inhibitor combinations might also be present in typical DOAC patients with long-term polypharmacy and DDI trials are needed that investigate the effect of drug combinations on DOAC exposure and efficacy.

A combination of increased absorption and reduced elimination can also lead to increased DOAC exposure that has previously not been investigated. A physiologically based pharmacokinetic model calculated that dabigatran $C_{\min }$ will significantly increase in patients with moderate renal impairment who concomitantly take the P-gp inhibitor verapamil [72]. Despite the statement in the product label that only recommends a dose reduction to $110 \mathrm{mg}$ twice daily, the authors suggested that the significantly increased $C_{\min }$ values might be preventable by reducing dabigatran doses further to $75 \mathrm{mg}$ twice daily [72]. However, as long as clinical trials investigating pharmacokinetics and clinical effects of this complex clinical situation are missing, it will be unclear whether patients treated with $110 \mathrm{mg}$ twice daily are at an increased risk of bleeding and what dabigatran efficacy will be if doses are further reduced. Interestingly, thorough analyses of the concentration measurements of the pivotal dabigatran trial RE-LY (Randomized Evaluation of Long-Term Anticoagulation Therapy) revealed that higher $C_{\min }$ values only slightly improved the benefit prediction $\leq 0.5$ and $\geq 2 .{ }^{1}$ Ketoconazole $400 \mathrm{mg}$ investigated. ${ }^{2}$ DOAC microdoses administered. ${ }^{3}$ Trial was performed in patients with moderate renal impairment. ${ }^{4}$ Rivaroxaban $40 \mathrm{mg}$ administered. ${ }^{5}$ Ketoconazole $200 \mathrm{mg}$ investigated. ${ }^{6}$ Trial was performed in patients with mild renal impairment. ${ }^{7}$ Rivaroxaban $10 \mathrm{mg}$ administered. ${ }^{8}$ The antacid mixture was composed of aluminium hydroxide and magnesium hydroxide. ${ }^{9}$ Rifampicin was given repeatedly

(ischemic stroke, systemic embolic events) and contributed more to the risk prediction (major bleeding events) [12].

Knowledge on the potential effect of inducers of CYP isozymes or drug transporters is also limited. Such drugs can limit DOAC absorption and foster elimination, thus reducing exposure. The product information provides vague information on these DDIs and advises to avoid a concomitant intake of a DOAC with inducing agents such as carbamazepine, dexamethasone, phenobarbital (and its prodrug primidone), rifampicin, or St. John's wort [2, 22-25]. Nevertheless, patients with epilepsy who are well-controlled with carbamazepine or patients with tuberculosis, who often require rifampicin therapy, cannot be easily switched to alternative drugs in order to avoid the combination of a DOAC with strong CYP3A4 or P-gp inducers. Thus, avoiding the inducer in order to initiate DOAC therapy is often not feasible and DOAC patients are switched to vitamin $\mathrm{K}$ antagonists because physicians believe that in this situation the established therapeutic concentration ranges provide a safer and more effective anticoagulation than current DOAC therapies [73]. However, vitamin $\mathrm{K}$ antagonists have a higher risk of fatal intracranial bleeding and DOAC exposure decreases might also be well-managed by increasing the DOAC dose and monitoring its immediate effects on 
anticoagulation. Still, the impact on DOAC exposure can vary substantially between the inducing agents, making dose adjustment complicated. For example, St. John's wort reduced rivaroxaban exposure by $26 \%$ and thus had only a minimal impact on rivaroxaban exposure compared with rifampicin (50\%) [74].

\section{Therapeutic Drug Monitoring}

Current management mostly relies on classical interaction trials that investigated the effect of an interacting drug on DOAC pharmacokinetics and rarely relies on trials that investigated the effect of DDIs on clinical endpoints. Thus, DOAC manufacturers and regulatory authorities have individually determined the percentage of DOAC exposure alteration that is critical for each DOAC and often provide vague clinical management for DDIs. However, subanalyses of data from the ENGAGE-AF TIMI 48 trial revealed that edoxaban patients taking the P-gp inhibitor amiodarone had fewer ischemic events and no increased bleeding risk if they took edoxaban $30 \mathrm{mg}$ instead of $60 \mathrm{mg}$ once daily [75]. The dose reduction was based on the DDI data where amiodarone increased edoxaban exposure by $40 \%$ [76]. Thus, adjusting DOAC doses according to plasma concentrations (therapeutic concentration monitoring) might be an option to treat DOAC patients optimally. However, a pre-requisite will be an established concentration effect relationship for both benefit (i.e., protection against systemic embolic events) and risk (bleeding).

This might further be of help for complex clinical situations such as polypharmacy, particularly if more than one major elimination pathway is impaired. Clear dosing guidelines in these situations are needed because in the absence of evidence, and mindful of bleeding events, physicians tend to reduce DOAC doses [77], which can preclude optimum treatment responses. As demonstrated in patients taking apixaban, underdosed DOAC patients have an increased risk of thromboembolic events (fivefold increased risk of stroke) [78]. Establishing therapeutic ranges could help detect patients who are exposed to supratherapeutic or subtherapeutic DOAC exposure and might help physicians to select the correct DOAC dose.

However, one therapeutic concentration range for each DOAC might not effectively protect every DOAC patient from the adverse effects of DOAC therapy. Depending on the indication, DOACs are used at different doses and dosage regimens. Therefore, patients taking rivaroxaban $2.5 \mathrm{mg}$ twice daily for the prevention of atherothrombotic events after an acute coronary syndrome will have lower AUC and $C_{\text {max }}$ but higher $C_{\min }$ values than patients with non-valvular atrial fibrillation taking rivaroxaban $20 \mathrm{mg}$ once daily for the prevention of stroke and systemic embolic events [79]. Thus, each DOAC indication probably requires its own therapeutic concentration range.

The width of the therapeutic concentration range defines the probability of bleeding and thrombotic events and possibly varies between different patient populations; some patient populations might tolerate larger concentration ranges than others. Patients co-administering drugs that impair thrombus formation are very likely to have a narrower therapeutic range than patients who are not because a concomitant drug reducing platelet aggregation in addition to the fibrin formation inhibition by a DOAC increases a patient's risk of bleeding. This mechanism forms undesirable, but clinically common, types of pharmacodynamic DDIs. Platelet aggregation inhibitors triggering such DDIs are cyclo-oxygenase inhibitors (e.g., acetylsalicylic acid or naproxen) or antagonists of the platelet receptor $\mathrm{P} 2 \mathrm{Y}_{12}$ (e.g., clopidogrel or ticagrelor). Results from DDI trials in healthy volunteers have indicated that concomitant intake of a DOAC and an antiplatelet agent (acetylsalicylic acid or clopidogrel) or a non-steroidal anti-inflammatory drug (naproxen) will increase the risk of bleeding because the bleeding time (a surrogate marker for bleeding events) substantially increased in these trials [80-85]. Data from pivotal DOAC trials and post-marketing studies verified that these combinations can relevantly increase bleeding events in anticoagulated patients, irrespective of the anticoagulant taken [86-90]. Subgroup analyses of and meta-analyses with data from pivotal DOAC trials in patients with non-valvular atrial fibrillation estimated that an additional intake of a single antiplatelet agent such as acetylsalicylic acid increases the risk of major bleeding 1.3-fold [86, 87]. The risk doubles in DOAC patients taking dual antiplatelet therapy [86, 91] and increases dose dependently, as shown in a prospective placebo-controlled trial evaluating the effect of increasing doses of apixaban [92]. Furthermore, DOAC labels highlight that selective serotonin reuptake inhibitors can also increase the risk of bleeding because patients in both investigational groups (warfarin and dabigatran) of the RE-LY trial had an increased risk of bleeding [22-25], an effect that is only incompletely understood [93].

A retrospective evaluation of Taiwanese health insurance data indicates that therapeutic concentration ranges will differ between patient populations [94]. In contrast to the presumed bleeding risk expressed in trials assessing DOAC DDIs of erythromycin and clarithromycin (moderate to strong CYP3A and P-gp inhibitors), these epidemiologic data revealed no increased risk of (major) bleeding [94]. Similarly, and unexpectedly, patients co-administering a DOAC and the CYP3A4 and P-gp inducer phenytoin presented with an increased risk of bleeding [94]. However, this retrospective evaluation did not evaluate important data such as renal function, DOAC doses, and adherence [94]. Renal impairment is an independent risk factor for bleeding 
and thrombosis $[95,96]$ and missing data on DOAC doses and adherence can erroneously suggest that a co-medication that usually increases DOAC plasma concentrations did not affect a patient's risk of bleeding.

In summary, while it may appear intuitive to measure DOAC concentrations and adjust DOAC doses accordingly, such an approach should not uncritically be applied until we know which pharmacokinetic parameter to monitor and whether it is predictive for both potential benefits and risks of DOACs. Moreover, given the diverging observations reported for individual DOACs [12, 13, 19-21], there might even be differences to be observed for individual DOACs. The RE-ALIGN (Randomized, Phase II Study to Evaluate the Safety and Pharmacokinetics of Oral Dabigatran Etexilate in Patients after Heart Valve Replacement) trial was terminated prematurely because the concentration-based dose adjustment of dabigatran excessively increased bleeding and thrombotic events in patients [97]. This trial demonstrated that adjusting dabigatran doses to $C_{\min }$ measurements was not beneficial. However, monitoring $C_{\min }$ and adjusting doses if they fell below an exploratory limit of $50 \mathrm{ng} /$ $\mathrm{mL}$ might not represent the optimal therapeutic range for the investigated high-risk patient population (patients with mechanical heart valves). Without clarity about the pharmacokinetic parameters that need to be monitored for optimal DOAC therapy and without evidence on the risk-benefit balance of concentration-based DOAC dose adjustments, DOAC doses should not be adjusted according to DOAC concentration measurements.

\section{Conclusion and Outlook}

DOAC concentrations in plasma seem to be important for DOAC therapy. Patients mainly risk bleeding events if plasma concentrations increase substantially and they can experience diminished protection from thromboembolic events if plasma concentrations are too low. DDIs might reduce the benefits of DOAC therapy because they can alter DOAC plasma concentrations significantly. DOACs appear to have less DDI potential than vitamin K antagonists, but complex DDIs fostered by polypharmacy or DDIs in patients with relevant co-morbidities have not been investigated thoroughly. Complex DDIs are present in typical DOAC patients because they are often renally impaired or take multiple drugs that might influence drug-metabolizing enzymes or drug transporters in a clinically significant manner. Without knowing the major potential DDIs and without good clinical management of these complex DDIs, DOAC patients might risk bleeding or ineffective anticoagulation. Establishing therapeutic concentration ranges for DOACs might improve current therapy because it would provide safety margins and might provide optimal therapy for polypharmacy patients.
However, currently, DOAC dose adjustments based on concentration measurements cannot be recommended because evidence-based data are missing. Patients' co-medications should be checked regularly in order to support the risk assessment for excessive bleeding or thrombotic events due to DDIs.

Acknowledgements Open Access funding provided by Projekt DEAL.

\section{Compliance with Ethical Standards}

Funding This project has received funding from the European Union's Horizon 2020 research and innovation program under Grant Agreement No. 754517.

Conflict of interest KIF and SH declare that they have no potential conflicts of interest that might be relevant to the contents of this manuscript. GM received consulting honoraria and data and safety monitoring board honoraria from Boehringer Ingelheim and Bayer outside the submitted work. WEH received consulting honoraria, speaker's honoraria, and travel support from BMS, Boehringer Ingelheim, and Daiichi Sankyo and research support from Bayer and Daichii-Sankyo outside the submitted work.

Open Access This article is licensed under a Creative Commons Attribution-Non-commercial 4.0 International License, which permits any non-commercial use, sharing, adaptation, distribution and reproduction in any medium or format, as long as you give appropriate credit to the original author(s) and the source, provide a link to the Creative Commons licence, and indicate if changes were made. The images or other third party material in this article are included in the article's Creative Commons licence, unless indicated otherwise in a credit line to the material. If material is not included in the article's Creative Commons licence and your intended use is not permitted by statutory regulation or exceeds the permitted use, you will need to obtain permission directly from the copyright holder. To view a copy of this licence, visit http://creativecommons.org/licenses/by-nc/4.0/.

\section{References}

1. Wong PC, Crain EJ, Xin B, Wexler RR, Lam PY, Pinto DJ, et al. Apixaban, an oral, direct and highly selective factor Xa inhibitor: in vitro, antithrombotic and antihemostatic studies. J Thromb Haemost. 2008;6(5):820-9. https://doi.org/10.111 1/j.1538-7836.2008.02939.x.

2. U.S. Food and Drug Administration. Betrixaban: clinical pharmacology and biopharmaceutics review; 2016. https://www.acces sdata.fda.gov/drugsatfda_docs/nda/2017/208383Orig1s000ClinP harmR.pdf. Accessed 29 Jan 2020.

3. Hauel NH, Nar H, Priepke H, Ries U, Stassen JM, Wienen W. Structure-based design of novel potent nonpeptide thrombin inhibitors. J Med Chem. 2002;45(9):1757-66. https://doi. org/10.1021/jm0109513.

4. Furugohri T, Isobe K, Honda Y, Kamisato-Matsumoto C, Sugiyama N, Nagahara T, et al. DU-176b, a potent and orally active factor Xa inhibitor: in vitro and in vivo pharmacological profiles. J Thromb Haemost. 2008;6(9):1542-9. https://doi.org/10 $.1111 /$ j.1538-7836.2008.03064.x.

5. Perzborn E, Strassburger J, Wilmen A, Pohlmann J, Roehrig S, Schlemmer KH, et al. In vitro and in vivo studies of the novel antithrombotic agent BAY 59-7939-an oral, direct Factor Xa 
inhibitor. J Thromb Haemost. 2005;3(3):514-21. https://doi.org /10.1111/j.1538-7836.2005.01166.x.

6. Wang X, Tirucherai G, Marbury TC, Wang J, Chang M, Zhang D, et al. Pharmacokinetics, pharmacodynamics, and safety of apixaban in subjects with end-stage renal disease on hemodialysis. J Clin Pharmacol. 2016;56(5):628-36. https://doi.org/10.1002/ jcph.628.

7. Stangier J, Rathgen K, Stahle H, Gansser D, Roth W. The pharmacokinetics, pharmacodynamics and tolerability of dabigatran etexilate, a new oral direct thrombin inhibitor, in healthy male subjects. Br J Clin Pharmacol. 2007;64(3):292-303. https://doi. org/10.1111/j.1365-2125.2007.02899.x.

8. Parasrampuria DA, Truitt KE. Pharmacokinetics and pharmacodynamics of edoxaban, a non-vitamin $\mathrm{K}$ antagonist oral anticoagulant that inhibits clotting factor Xa. Clin Pharmacokinet. 2016;55(6):641-55. https://doi.org/10.1007/s40262-015-0342-7.

9. Kubitza D, Becka M, Wensing G, Voith B, Zuehlsdorf M. Safety, pharmacodynamics, and pharmacokinetics of BAY 59-7939—an oral, direct Factor Xa inhibitor - after multiple dosing in healthy male subjects. Eur J Clin Pharmacol. 2005;61(12):873-80. https ://doi.org/10.1007/s00228-005-0043-5.

10. Connolly SJ, Milling TJ Jr, Eikelboom JW, Gibson CM, Curnutte JT, Gold A, et al. Andexanet alfa for acute major bleeding associated with factor Xa inhibitors. N Engl J Med. 2016;375(12):1131-41. https://doi.org/10.1056/NEJMoa1607 887.

11. Pollack CV Jr, Reilly PA, van Ryn J, Eikelboom JW, Glund S, Bernstein RA, et al. Idarucizumab for dabigatran reversal - full cohort analysis. N Engl J Med. 2017;377(5):431-41. https://doi. org/10.1056/NEJMoa1707278.

12. Reilly PA, Lehr T, Haertter S, Connolly SJ, Yusuf S, Eikelboom JW, et al. The effect of dabigatran plasma concentrations and patient characteristics on the frequency of ischemic stroke and major bleeding in atrial fibrillation patients: the RE-LY Trial (Randomized Evaluation of Long-Term Anticoagulation Therapy). J Am Coll Cardiol. 2014;63(4):321-8. https://doi. org/10.1016/j.jacc.2013.07.104.

13. Ruff CT, Giugliano RP, Braunwald E, Morrow DA, Murphy SA, Kuder JF, et al. Association between edoxaban dose, concentration, anti-Factor Xa activity, and outcomes: an analysis of data from the randomised, double-blind ENGAGE AF-TIMI 48 trial. Lancet. 2015;385(9984):2288-95. https://doi.org/10.1016/s0140 -6736(14)61943-7.

14. Herink MC, Zhuo YF, Williams CD, DeLoughery TG. Clinical management of pharmacokinetic drug interactions with direct oral anticoagulants (DOACs). Drugs. 2019;79(15):1625-34. https://doi.org/10.1007/s40265-019-01183-0.

15. Connolly SJ, Ezekowitz MD, Yusuf S, Eikelboom J, Oldgren J, Parekh A, et al. Dabigatran versus warfarin in patients with atrial fibrillation. N Engl J Med. 2009;361(12):1139-51. https://doi. org/10.1056/NEJMoa0905561.

16. Granger CB, Alexander JH, McMurray JJ, Lopes RD, Hylek EM, Hanna M, et al. Apixaban versus warfarin in patients with atrial fibrillation. N Engl J Med. 2011;365(11):981-92. https://doi. org/10.1056/NEJMoa1107039.

17. Giugliano RP, Ruff CT, Braunwald E, Murphy SA, Wiviott SD, Halperin JL, et al. Edoxaban versus warfarin in patients with atrial fibrillation. N Engl J Med. 2013;369(22):2093-104. https ://doi.org/10.1056/NEJMoa1310907.

18. Patel MR, Mahaffey KW, Garg J, Pan G, Singer DE, Hacke $\mathrm{W}$, et al. Rivaroxaban versus warfarin in nonvalvular atrial fibrillation. N Engl J Med. 2011;365(10):883-91. https://doi. org/10.1056/NEJMoa1009638.

19. Weitz JI, Connolly SJ, Patel I, Salazar D, Rohatagi S, Mendell $\mathrm{J}$, et al. Randomised, parallel-group, multicentre, multinational phase 2 study comparing edoxaban, an oral factor Xa inhibitor, with warfarin for stroke prevention in patients with atrial fibrillation. Thromb Haemost. 2010;104(3):633-41. https://doi. org/10.1160/th10-01-0066.

20. Leil TA, Feng Y, Zhang L, Paccaly A, Mohan P, Pfister M. Quantification of apixaban's therapeutic utility in prevention of venous thromboembolism: selection of phase III trial dose. Clin Pharmacol Ther. 2010;88(3):375-82. https://doi.org/10.1038/ clpt.2010.106.

21. Sakaguchi T, Osanai H, Murase Y, Ishii H, Nakashima Y, Asano $\mathrm{H}$, et al. Monitoring of anti-Xa activity and factors related to bleeding events: a study in Japanese patients with nonvalvular atrial fibrillation receiving rivaroxaban. J Cardiol. 2017;70(3):244-9. https://doi.org/10.1016/j.jjcc.2016.11.013.

22. European Medicines Agency. Eliquis: summary of product characteristics; 2016. http://www.ema.europa.eu/docs/en_GB/ document_library/EPAR_-_Product_Information/human/00214 8/WC500107728.pdf. Accessed 29 Jan 2020.

23. European Medicines Agency. Pradaxa: summary of product characteristics; 2018. http://www.ema.europa.eu/docs/en_GB/ document_library/EPAR_-_Product_Information/human/00082 9/WC500041059.pdf. Accessed 29 Jan 2020.

24. European Medicines Agency. Lixiana: summary of product characteristics; 2015. https://www.ema.europa.eu/documents/ product-information/lixiana-epar-product-information_en.pdf. Accessed 29 Jan 2020.

25. European Medicines Agency. Xarelto: summary of product characteristics; 2013. http://www.ema.europa.eu/docs/en_GB/ document_library/EPAR_-_Product_Information/human/00094 4/WC500057108.pdf. Accessed 29 Jan 2020.

26. Kirchhof P, Benussi S, Kotecha D, Ahlsson A, Atar D, Casadei B, et al. 2016 ESC guidelines for the management of atrial fibrillation developed in collaboration with EACTS. Eur Heart J. 2016;37(38):2893-962. https://doi.org/10.1093/eurheartj/ehw21 0 .

27. Martinez BK, Baker WL, Sood NA, Bunz TJ, Meinecke AK, Eriksson D, et al. Influence of polypharmacy on the effectiveness and safety of rivaroxaban versus warfarin in patients with nonvalvular atrial fibrillation. Pharmacotherapy. 2019;39(2):196-203. https://doi.org/10.1002/phar.2213.

28. Piccini JP, Hellkamp AS, Washam JB, Becker RC, Breithardt G, Berkowitz SD, et al. Polypharmacy and the efficacy and safety of rivaroxaban versus warfarin in the prevention of stroke in patients with nonvalvular atrial fibrillation. Circulation. 2016;133(4):352-60. https://doi.org/10.1161/circulatio naha.115.018544.

29. Jaspers Focks J, Brouwer MA, Wojdyla DM, Thomas L, Lopes RD, Washam JB, et al. Polypharmacy and effects of apixaban versus warfarin in patients with atrial fibrillation: post hoc analysis of the ARISTOTLE trial. BMJ (Clin Res Ed). 2016;353:i2868. https://doi.org/10.1136/bmj.i2868.

30. Proietti M, Raparelli V, Olshansky B, Lip GY. Polypharmacy and major adverse events in atrial fibrillation: observations from the AFFIRM trial. Clin Res Cardiol. 2016;105(5):412-20. https ://doi.org/10.1007/s00392-015-0936-y.

31. Harskamp RE, Teichert M, Lucassen WAM, van Weert H, Lopes RD. Impact of polypharmacy and P-glycoprotein- and CYP3A4modulating drugs on safety and efficacy of oral anticoagulation therapy in patients with atrial fibrillation. Cardiovasc Drugs Ther. 2019;33(5):615-23. https://doi.org/10.1007/s10557-01906907-8.

32. Vakkalagadda B, Frost C, Byon W, Boyd RA, Wang J, Zhang D, et al. Effect of rifampin on the pharmacokinetics of apixaban, an oral direct inhibitor of factor Xa. Am J Cardiovasc Drugs. 2016;16(2):119-27. https://doi.org/10.1007/s40256-015-0157-9.

33. Hodin S, Basset T, Jacqueroux E, Delezay O, Clotagatide A, Perek N, et al. In vitro comparison of the role of p-glycoprotein 
and breast cancer resistance protein on direct oral anticoagulants disposition. Eur J Drug Metab Pharmacokinet. 2018;43(2):18391. https://doi.org/10.1007/s13318-017-0434-x.

34. Frost C, Nepal S, Wang J, Schuster A, Byon W, Boyd RA, et al. Safety, pharmacokinetics and pharmacodynamics of multiple oral doses of apixaban, a factor Xa inhibitor, in healthy subjects. $\mathrm{Br}$ J Clin Pharmacol. 2013;76(5):776-86. https://doi.org/10.1111/ bcp. 12106 .

35. Frost C, Wang J, Nepal S, Schuster A, Barrett YC, MosquedaGarcia R, et al. Apixaban, an oral, direct factor Xa inhibitor: single dose safety, pharmacokinetics, pharmacodynamics and food effect in healthy subjects. Br J Clin Pharmacol. 2013;75(2):47687. https://doi.org/10.1111/j.1365-2125.2012.04369.x.

36. Upreti VV, Song Y, Wang J, Byon W, Boyd RA, Pursley JM, et al. Effect of famotidine on the pharmacokinetics of apixaban, an oral direct factor Xa inhibitor. Clin Pharmacol. 2013;5:59-66. https://doi.org/10.2147/CPAA.S41999.

37. Zhang D, He K, Herbst JJ, Kolb J, Shou W, Wang L, et al. Characterization of efflux transporters involved in distribution and disposition of apixaban. Drug Metab Dispos. 2013;41(4):827-35. https://doi.org/10.1124/dmd.112.050260.

38. Raghavan N, Frost CE, Yu Z, He K, Zhang H, Humphreys WG, et al. Apixaban metabolism and pharmacokinetics after oral administration to humans. Drug Metab Dispos. 2009;37(1):7481. https://doi.org/10.1124/dmd.108.023143.

39. Wang L, Raghavan N, He K, Luettgen JM, Humphreys WG, Knabb RM, et al. Sulfation of o-demethyl apixaban: enzyme identification and species comparison. Drug Metab Dispos. 2009;37(4):802-8. https://doi.org/10.1124/dmd.108.025593.

40. Wang X, Mondal S, Wang J, Tirucherai G, Zhang D, Boyd RA, et al. Effect of activated charcoal on apixaban pharmacokinetics in healthy subjects. Am J Cardiovasc Drugs. 2014;14(2):147-54. https://doi.org/10.1007/s40256-013-0055-y.

41. Wang L, He K, Maxwell B, Grossman SJ, Tremaine LM, Humphreys WG, et al. Tissue distribution and elimination of $\left[{ }^{14} \mathrm{C}\right]$ apixaban in rats. Drug Metab Dispos. 2011;39(2):256-64. https ://doi.org/10.1124/dmd.110.036442.

42. Chang M, Yu Z, Shenker A, Wang J, Pursley J, Byon W, et al. Effect of renal impairment on the pharmacokinetics, pharmacodynamics, and safety of apixaban. J Clin Pharmacol. 2016;56(5):637-45. https://doi.org/10.1002/jcph.633.

43. Frost CE, Byon W, Song Y, Wang J, Schuster AE, Boyd RA, et al. Effect of ketoconazole and diltiazem on the pharmacokinetics of apixaban, an oral direct factor Xa inhibitor. Br J Clin Pharmacol. 2015;79(5):838-46. https://doi.org/10.1111/bcp.12541.

44. Chan NC, Bhagirath V, Eikelboom JW. Profile of betrixaban and its potential in the prevention and treatment of venous thromboembolism. Vasc Health Risk Manag. 2015;11:343-51. https:// doi.org/10.2147/vhrm.S63060.

45. Baker DE. Formulary drug review: betrixaban. Hosp Pharm. 2018;53(1):29-37. https://doi.org/10.1177/0018578717739397.

46. U.S. Food and Drug Administration. Product label betrixaban; 2017. https://www.accessdata.fda.gov/drugsatfda_docs/label /2017/208383s000lbl.pdf. Accessed 29 Jan 2020.

47. U.S. Food and Drug Administration. Dabigatran: chemistry review; 2010. https://www.accessdata.fda.gov/drugsatfda_docs/ nda/2010/022512Orig1s000ChemR_Corrrected\%203.11.2011. pdf. Accessed 29 Jan 2020.

48. Blech S, Ebner T, Ludwig-Schwellinger E, Stangier J, Roth W. The metabolism and disposition of the oral direct thrombin inhibitor, dabigatran, in humans. Drug Metab Dispos. 2008;36(2):386-99. https://doi.org/10.1124/dmd.107.019083.

49. Laizure SC, Parker RB, Herring VL, Hu ZY. Identification of carboxylesterase-dependent dabigatran etexilate hydrolysis. Drug Metab Dispos. 2014;42(2):201-6. https://doi.org/10.1124/ dmd.113.054353.
50. Ishiguro N, Kishimoto W, Volz A, Ludwig-Schwellinger E, Ebner T, Schaefer O. Impact of endogenous esterase activity on in vitro p-glycoprotein profiling of dabigatran etexilate in Caco-2 monolayers. Drug Metab Dispos. 2014;42(2):250-6. https://doi. org/10.1124/dmd.113.053561.

51. Ebner T, Wagner K, Wienen W. Dabigatran acylglucuronide, the major human metabolite of dabigatran: in vitro formation, stability, and pharmacological activity. Drug Metab Dispos. 2010;38(9):1567-75. https://doi.org/10.1124/dmd.110.033696.

52. Hartter S, Sennewald R, Nehmiz G, Reilly P. Oral bioavailability of dabigatran etexilate $\left(\operatorname{Pradaxa}^{\circledR}\right)$ after co-medication with verapamil in healthy subjects. Br J Clin Pharmacol. 2013;75(4):105362. https://doi.org/10.1111/j.1365-2125.2012.04453.x.

53. Troconiz IF, Tillmann C, Liesenfeld KH, Schafer HG, Stangier J. Population pharmacokinetic analysis of the new oral thrombin inhibitor dabigatran etexilate (BIBR 1048) in patients undergoing primary elective total hip replacement surgery. J Clin Pharmacol. 2007;47(3):371-82. https://doi.org/10.1177/0091270006297228.

54. Stangier J, Rathgen K, Stahle H, Mazur D. Influence of renal impairment on the pharmacokinetics and pharmacodynamics of oral dabigatran etexilate: an open-label, parallel-group, singlecentre study. Clin Pharmacokinet. 2010;49(4):259-68. https:// doi.org/10.2165/11318170-000000000-00000.

55. Matsushima N, Lee F, Sato T, Weiss D, Mendell J. Bioavailability and safety of the factor Xa inhibitor edoxaban and the effects of quinidine in healthy subjects. Clin Pharmacol Drug Dev. 2013;2(4):358-66. https://doi.org/10.1002/cpdd.53.

56. Mikkaichi T, Yoshigae Y, Masumoto H, Imaoka T, Rozehnal $\mathrm{V}$, Fischer T, et al. Edoxaban transport via p-glycoprotein is a key factor for the drug's disposition. Drug Metab Dispos. 2014;42(4):520-8. https://doi.org/10.1124/dmd.113.054866.

57. Bathala MS, Masumoto H, Oguma T, He L, Lowrie C, Mendell J. Pharmacokinetics, biotransformation, and mass balance of edoxaban, a selective, direct factor Xa inhibitor, in humans. Drug Metab Dispos. 2012;40(12):2250-5. https://doi.org/10.1124/ dmd.112.046888.

58. Matsushima N, Mendell J, Zahir H, Lee F, Sato T, Jin J, et al. Abstracts annual meeting of the American Society for Clinical Pharmacology and Therapeutics March 14-17, 2012 National Harbor, Maryland (PI-72). Clin Pharmacol Ther. 2012;91(Suppl 1):S7-47.

59. Mendell J, Chen S, He L, Desai M, Parasramupria DA. The effect of rifampin on the pharmacokinetics of edoxaban in healthy adults. Clin Drug Investig. 2015;35(7):447-53. https://doi. org/10.1007/s40261-015-0298-2.

60. Stampfuss J, Kubitza D, Becka M, Mueck W. The effect of food on the absorption and pharmacokinetics of rivaroxaban. Int J Clin Pharmacol Ther. 2013;51(7):549-61. https://doi.org/10.5414/ cp201812.

61. Gnoth MJ, Buetehorn U, Muenster U, Schwarz T, Sandmann S. In vitro and in vivo P-glycoprotein transport characteristics of rivaroxaban. J Pharmacol Exp Ther. 2011;338(1):372-80. https ://doi.org/10.1124/jpet.111.180240.

62. Kubitza D, Becka M, Zuehlsdorf M, Mueck W. Effect of food, an antacid, and the $\mathrm{H} 2$ antagonist ranitidine on the absorption of BAY 59-7939 (rivaroxaban), an oral, direct factor Xa inhibitor, in healthy subjects. J Clin Pharmacol. 2006;46(5):549-58. https ://doi.org/10.1177/0091270006286904.

63. Mueck W, Kubitza D, Becka M. Co-administration of rivaroxaban with drugs that share its elimination pathways: pharmacokinetic effects in healthy subjects. Br J Clin Pharmacol. 2013;76(3):455-66. https://doi.org/10.1111/bcp.12075.

64. Weinz C, Schwarz T, Kubitza D, Mueck W, Lang D. Metabolism and excretion of rivaroxaban, an oral, direct factor Xa inhibitor, in rats, dogs, and humans. Drug Metab Dispos. 2009;37(5):105664. https://doi.org/10.1124/dmd.108.025569. 
65. Kubitza D, Becka M, Mueck W, Halabi A, Maatouk H, Klause $\mathrm{N}$, et al. Effects of renal impairment on the pharmacokinetics, pharmacodynamics and safety of rivaroxaban, an oral, direct Factor Xa inhibitor. Br J Clin Pharmacol. 2010;70(5):703-12. https ://doi.org/10.1111/j.1365-2125.2010.03753.x.

66. Kubitza D, Becka M, Roth A, Mueck W. The influence of age and gender on the pharmacokinetics and pharmacodynamics of rivaroxaban - an oral, direct Factor Xa inhibitor. J Clin Pharmacol. 2013;53(3):249-55. https://doi.org/10.1002/jcph.5.

67. Pare G, Eriksson N, Lehr T, Connolly S, Eikelboom J, Ezekowitz $\mathrm{MD}$, et al. Genetic determinants of dabigatran plasma levels and their relation to bleeding. Circulation. 2013;127(13):1404-12. https://doi.org/10.1161/circulationaha.112.001233.

68. Ueshima S, Hira D, Fujii R, Kimura Y, Tomitsuka C, Yamane $\mathrm{T}$, et al. Impact of $\mathrm{ABCB} 1, \mathrm{ABCG} 2$, and CYP3A5 polymorphisms on plasma trough concentrations of apixaban in Japanese patients with atrial fibrillation. Pharmacogenet Genomics. 2017;27(9):329-36. https://doi.org/10.1097/fpc.0000000000 000294.

69. Moore KT, Vaidyanathan S, Natarajan J, Ariyawansa J, Haskell L, Turner KC. An open-label study to estimate the effect of steady-state erythromycin on the pharmacokinetics, pharmacodynamics, and safety of a single dose of rivaroxaban in subjects with renal impairment and normal renal function. J Clin Pharmacol. 2014;54(12):1407-20. https://doi.org/10.1002/jcph.352.

70. European Medicines Agency. Maviret: summary of product characteristics; 2017. http://www.ema.europa.eu/docs/en_GB/ document_library/EPAR___Product_Information/human/00443 0/WC500233677.pdf. Accessed 29 Jan 2020.

71. European Medicines Agency. Vosevi: summary of product characteristics; 2019. https://www.ema.europa.eu/en/documents/ product-information/vosevi-epar-product-information_en.pdf. Accessed 29 Jan 2020.

72. Doki K, Neuhoff S, Rostami-Hodjegan A, Homma M. Assessing potential drug-drug interactions between dabigatran etexilate and a P-glycoprotein inhibitor in renal impairment populations using physiologically based pharmacokinetic modeling. CPT Pharmacomet Syst Pharmacol. 2019;8(2):118-26. https://doi. org/10.1002/psp4.12382.

73. Galgani A, Palleria C, Iannone LF, De Sarro G, Giorgi FS, Maschio M, et al. Pharmacokinetic interactions of clinical interest between direct oral anticoagulants and antiepileptic drugs. Front Neurol. 2018;9:1067. https://doi.org/10.3389/fneur .2018.01067.

74. Huppertz A, Werntz L, Meid AD, Foerster KI, Burhenne J, Czock D, et al. Rivaroxaban and macitentan can be coadministered without dose adjustment but the combination of rivaroxaban and St John's wort should be avoided. Br J Clin Pharmacol. 2018;84(12):2903-13. https://doi.org/10.1111/bcp.13757.

75. Steffel J, Giugliano RP, Braunwald E, Murphy SA, Atar D, Heidbuchel H, et al. Edoxaban vs. warfarin in patients with atrial fibrillation on amiodarone: a subgroup analysis of the ENGAGE AF-TIMI 48 trial. Eur Heart J. 2015;36(33):2239-45. https://doi. org/10.1093/eurheartj/ehv201.

76. Mendell J, Zahir H, Matsushima N, Noveck R, Lee F, Chen S, et al. Drug-drug interaction studies of cardiovascular drugs involving P-glycoprotein, an efflux transporter, on the pharmacokinetics of edoxaban, an oral factor Xa inhibitor. Am J Cardiovasc Drugs. 2013;13(5):331-42. https://doi.org/10.1007/s4025 6-013-0029-0.

77. Devereaux PJ, Anderson DR, Gardner MJ, Putnam W, Flowerdew GJ, Brownell BF, et al. Differences between perspectives of physicians and patients on anticoagulation in patients with atrial fibrillation: observational study. BMJ (Clin Res Ed). 2001;323(7323):1218-22. https://doi.org/10.1136/ bmj.323.7323.1218.
78. Yao X, Shah ND, Sangaralingham LR, Gersh BJ, Noseworthy PA. Non-vitamin K antagonist oral anticoagulant dosing in patients with atrial fibrillation and renal dysfunction. J Am Coll Cardiol. 2017;69(23):2779-90. https://doi.org/10.1016/j. jacc.2017.03.600.

79. Mega JL, Braunwald E, Mohanavelu S, Burton P, Poulter R, Misselwitz F, et al. Rivaroxaban versus placebo in patients with acute coronary syndromes (ATLAS ACS-TIMI 46): a randomised, double-blind, phase II trial. Lancet. 2009;374(9683):29-38. https ://doi.org/10.1016/s0140-6736(09)60738-8.

80. U.S. Food and Drug Administration. Apixaban: clinical pharmacology and biopharmaceutics review; 2012. https://www.acces sdata.fda.gov/drugsatfda_docs/nda/2012/202155Orig1s000ClinP harmR.pdf. Accessed 29 Jan 2020.

81. Kubitza D, Becka M, Mueck W, Zuehlsdorf M. Safety, tolerability, pharmacodynamics, and pharmacokinetics of rivaroxaban-an oral, direct factor Xa inhibitor-are not affected by aspirin. J Clin Pharmacol. 2006;46(9):981-90. https://doi. org/10.1177/0091270006292127.

82. Kubitza D, Becka M, Muck W, Schwers S. Effect of co-administration of rivaroxaban and clopidogrel on bleeding time, pharmacodynamics and pharmacokinetics: a phase I study. Pharmaceuticals (Basel, Switzerland). 2012;5(3):279-96. https://doi. org/10.3390/ph5030279.

83. Kubitza D, Becka M, Mueck W, Zuehlsdorf M. Rivaroxaban (BAY 59-7939) — an oral, direct Factor Xa inhibitorhas no clinically relevant interaction with naproxen. Br J Clin Pharmacol. 2007;63(4):469-76. https://doi.org/10.111 1/j.1365-2125.2006.02776.x.

84. Mendell J, Lee F, Chen S, Worland V, Shi M, Samama MM. The effects of the antiplatelet agents, aspirin and naproxen, on pharmacokinetics and pharmacodynamics of the anticoagulant edoxaban, a direct factor Xa inhibitor. J Cardiovasc Pharmacol. 2013;62(2):212-21. https://doi.org/10.1097/FJC.0b013e3182 970991.

85. Frost C, Shenker A, Gandhi MD, Pursley J, Barrett YC, Wang J, et al. Evaluation of the effect of naproxen on the pharmacokinetics and pharmacodynamics of apixaban. Br J Clin Pharmacol. 2014;78(4):877-85. https://doi.org/10.1111/bcp.12393.

86. Dans AL, Connolly SJ, Wallentin L, Yang S, Nakamya J, Brueckmann M, et al. Concomitant use of antiplatelet therapy with dabigatran or warfarin in the Randomized Evaluation of Long-Term Anticoagulation Therapy (RE-LY) trial. Circulation. 2013;127(5):634-40. https://doi.org/10.1161/circulatio naha.112.115386.

87. Kumar S, Danik SB, Altman RK, Barrett CD, Lip GY, Chatterjee $\mathrm{S}$, et al. Non-vitamin $\mathrm{K}$ antagonist oral anticoagulants and antiplatelet therapy for stroke prevention in patients with atrial fibrillation: a meta-analysis of randomized controlled trials. Cardiol Rev. 2016;24(5):218-23. https://doi.org/10.1097/crd.00000 00000000088

88. Kreutz R, Haas S, Holberg G, Lassen MR, Mantovani LG, Schmidt A, et al. Rivaroxaban compared with standard thromboprophylaxis after major orthopaedic surgery: co-medication interactions. Br J Clin Pharmacol. 2016;81(4):724-34. https:// doi.org/10.1111/bcp.12836.

89. Eriksson BI, Rosencher N, Friedman RJ, Homering M, Dahl OE. Concomitant use of medication with antiplatelet effects in patients receiving either rivaroxaban or enoxaparin after total hip or knee arthroplasty. Thromb Res. 2012;130(2):147-51. https:// doi.org/10.1016/j.thromres.2011.12.005.

90. Davidson BL, Verheijen S, Lensing AW, Gebel M, Brighton TA, Lyons RM, et al. Bleeding risk of patients with acute venous thromboembolism taking nonsteroidal anti-inflammatory drugs or aspirin. JAMA Intern Med. 2014;174(6):947-53. https://doi. org/10.1001/jamainternmed.2014.946. 
91. Oldgren J, Wallentin L, Alexander JH, James S, Jonelid B, Steg $\mathrm{G}$, et al. New oral anticoagulants in addition to single or dual antiplatelet therapy after an acute coronary syndrome: a systematic review and meta-analysis. Eur Heart J. 2013;34(22):167080. https://doi.org/10.1093/eurheartj/eht049.

92. Alexander JH, Becker RC, Bhatt DL, Cools F, Crea F, Dellborg M, et al. Apixaban, an oral, direct, selective factor Xa inhibitor, in combination with antiplatelet therapy after acute coronary syndrome: results of the Apixaban for Prevention of Acute Ischemic and Safety Events (APPRAISE) trial. Circulation. 2009;119(22):2877-85. https://doi.org/10.1161/circulatio naha.108.832139.

93. Serebruany VL. Selective serotonin reuptake inhibitors and increased bleeding risk: are we missing something? Am J Med. 2006;119(2):113-6. https://doi.org/10.1016/j.amjme d.2005.03.044.

94. Chang SH, Chou IJ, Yeh YH, Chiou MJ, Wen MS, Kuo CT, et al. Association between use of non-vitamin $\mathrm{K}$ oral anticoagulants with and without concurrent medications and risk of major bleeding in nonvalvular atrial fibrillation. JAMA. 2017;318(13):12509. https://doi.org/10.1001/jama.2017.13883.

95. Go AS, Fang MC, Udaltsova N, Chang Y, Pomernacki NK, Borowsky L, et al. Impact of proteinuria and glomerular filtration rate on risk of thromboembolism in atrial fibrillation: the anticoagulation and risk factors in atrial fibrillation (ATRIA) study. Circulation. 2009;119(10):1363-9. https://doi.org/10.1161/circu lationaha.108.816082.

96. Olesen JB, Lip GY, Kamper AL, Hommel K, Kober L, Lane $\mathrm{DA}$, et al. Stroke and bleeding in atrial fibrillation with chronic kidney disease. N Engl J Med. 2012;367(7):625-35. https://doi. org/10.1056/NEJMoa1105594.

97. Eikelboom JW, Connolly SJ, Brueckmann M, Granger CB, Kappetein AP, Mack MJ, RE-ALIGN Investigators, et al. Dabigatran versus warfarin in patients with mechanical heart valves. N Engl J Med. 2013;369(13):1206-14. https://doi.org/10.1056/NEJMo a1300615.

98. Mikus G, Foerster KI, Schaumaeker M, Lehmann ML, Burhenne J, Haefeli WE. Microdosed cocktail of three oral factor Xa inhibitors to evaluate drug-drug interactions with potential perpetrator drugs. Clin Pharmacokinet. 2019;58(9):1155-63. https://doi. org/10.1007/s40262-019-00749-1.

99. Bashir B, Stickle DF, Chervoneva I, Kraft WK. Drug-drug interaction study of apixaban with cyclosporine and tacrolimus in healthy volunteers. Clin Transl Sci. 2018;11(6):590-6. https:// doi.org/10.1111/cts.12580.

100. Barrett YC, Wang J, Song Y, Pursley J, Wastall P, Wright R, et al. A randomised assessment of the pharmacokinetic, pharmacodynamic and safety interaction between apixaban and enoxaparin in healthy subjects. Thromb Haemost. 2012;107(5):916-24. https ://doi.org/10.1160/th11-09-0634.

101. Frost C, Song Y, Yu Z, Wang J, Lee LS, Schuster A, et al. The effect of apixaban on the pharmacokinetics of digoxin and atenolol in healthy subjects. Clin Pharmacol. 2017;9:19-28. https:// doi.org/10.2147/cpaa.S115687.

102. Prueksaritanont T, Tatosian DA, Chu X, Railkar R, Evers R, Chavez-Eng $\mathrm{C}$, et al. Validation of a microdose probe drug cocktail for clinical drug interaction assessments for drug transporters and CYP3A. Clin Pharmacol Ther. 2017;101(4):519-30. https:// doi.org/10.1002/cpt.525.

103. Delavenne X, Ollier E, Basset T, Bertoletti L, Accassat S, Garcin A, et al. A semi-mechanistic absorption model to evaluate drugdrug interaction with dabigatran: application with clarithromycin. Br J Clin Pharmacol. 2013;76(1):107-13. https://doi. org/10.1111/bcp.12055.

104. Gouin-Thibault I, Delavenne X, Blanchard A, Siguret V, Salem JE, Narjoz C, et al. Interindividual variability in dabigatran and rivaroxaban exposure: contribution of $\mathrm{ABCB} 1$ genetic polymorphisms and interaction with clarithromycin. J Thromb Haemost. 2017;15(2):273-83. https://doi.org/10.1111/jth.13577.

105. U.S. Food and Drug Administration. Dabigatran: clinical pharmacology and biopharmaceutics review; 2010. https://www.acces sdata.fda.gov/drugsatfda_docs/nda/2010/022512Orig1s000ClinP harmR_Corrrected\%203.11.2011.pdf. Accessed 29 Jan 2020.

106. Hartter S, Koenen-Bergmann M, Sharma A, Nehmiz G, Lemke U, Timmer W, et al. Decrease in the oral bioavailability of dabigatran etexilate after co-medication with rifampicin. Br J Clin Pharmacol. 2012;74(3):490-500. https://doi.org/10.111 $1 / \mathrm{j} .1365-2125.2012 .04218 . x$.

107. Liesenfeld KH, Lehr T, Dansirikul C, Reilly PA, Connolly SJ, Ezekowitz MD, et al. Population pharmacokinetic analysis of the oral thrombin inhibitor dabigatran etexilate in patients with non-valvular atrial fibrillation from the RE-LY trial. J Thromb Haemost. 2011;9(11):2168-75. https://doi.org/10.111 1/j.1538-7836.2011.04498.x.

108. Hartter S, Sennewald R, Schepers C, Baumann S, Fritsch H, Friedman J. Pharmacokinetic and pharmacodynamic effects of comedication of clopidogrel and dabigatran etexilate in healthy male volunteers. Eur J Clin Pharmacol. 2013;69(3):327-39. https ://doi.org/10.1007/s00228-012-1304-8.

109. Hsyu PH, Pignataro DS, Matschke K. Effect of bosutinib on the absorption of dabigatran etexilate mesylate, a P-glycoprotein substrate, in healthy subjects. Eur J Clin Pharmacol. 2017;73(1):5763. https://doi.org/10.1007/s00228-016-2115-0.

110. Stangier J, Stahle H, Rathgen K, Roth W, Reseski K, Kornicke T. Pharmacokinetics and pharmacodynamics of dabigatran etexilate, an oral direct thrombin inhibitor, with coadministration of digoxin. J Clin Pharmacol. 2012;52(2):243-50. https://doi. org/10.1177/0091270010393342.

111. Stangier J, Rathgen K, Stahle H, Reseski K, Kornicke T, Roth W. Coadministration of dabigatran etexilate and atorvastatin: assessment of potential impact on pharmacokinetics and pharmacodynamics. Am J Cardiovasc Drugs. 2009;9(1):59-68. https://doi. org/10.2165/00129784-200909010-00006.

112. Stangier J, Stahle H, Rathgen K, Fuhr R. Pharmacokinetics and pharmacodynamics of the direct oral thrombin inhibitor dabigatran in healthy elderly subjects. Clin Pharmacokinet. 2008;47(1):47-59. https://doi.org/10.2165/00003088-20084 7010-00005.

113. Kumar P, Gordon LA, Brooks KM, George JM, Kellogg A, McManus M, et al. Differential influence of the antiretroviral pharmacokinetic enhancers ritonavir and cobicistat on intestinal p-glycoprotein transport and the pharmacokinetic/pharmacodynamic disposition of dabigatran. Antimicrob Agents Chemother. 2017. https://doi.org/10.1128/AAC.01201-17.

114. Parasrampuria DA, Mendell J, Shi M, Matsushima N, Zahir H, Truitt K. Edoxaban drug-drug interactions with ketoconazole, erythromycin, and cyclosporine. Br J Clin Pharmacol. 2016. https://doi.org/10.1111/bcp.13092.

115. Mendell J, Noveck RJ, Shi M. Pharmacokinetics of the direct factor Xa inhibitor edoxaban and digoxin administered alone and in combination. J Cardiovasc Pharmacol. 2012;60(4):335-41. https ://doi.org/10.1097/FJC.0b013e31826265b6.

116. Zahir H, Matsushima N, Halim AB, He L, Zhang G, Lee F, et al. Edoxaban administration following enoxaparin: a pharmacodynamic, pharmacokinetic, and tolerability assessment in human subjects. Thromb Haemost. 2012;108(1):166-75. https://doi. org/10.1160/th11-09-0676.

117. U.S. Food and Drug Administration. Edoxaban: clinical pharmacology and biopharmaceutics review; 2014. https://www.acces sdata.fda.gov/drugsatfda_docs/nda/2015/206316Orig1Orig2s000 ClinPharmR.pdf. Accessed 29 Jan 2020. 
118. Brings A, Lehmann ML, Foerster KI, Burhenne J, Weiss J, Haefeli WE, et al. Perpetrator effects of ciclosporin (P-glycoprotein inhibitor) and its combination with fluconazole (CYP3A inhibitor) on the pharmacokinetics of rivaroxaban in healthy volunteers. Br J Clin Pharmacol. 2019;85(7):1528-37. https://doi. org/10.1111/bcp.13934.

119. Greenblatt DJ, Patel M, Harmatz JS, Nicholson WT, Rubino CM, Chow CR. Impaired rivaroxaban clearance in mild renal insufficiency with verapamil coadministration: potential implications for bleeding risk and dose selection. J Clin Pharmacol. 2018;58(4):533-40. https://doi.org/10.1002/jcph.1040.

120. Kubitza D, Becka M, Roth A, Mueck W. Absence of clinically relevant interactions between rivaroxaban - an oral, direct Factor Xa inhibitor-and digoxin or atorvastatin in healthy subjects. J Int Med Res. 2012;40(5):1688-707. https://doi. org/10.1177/030006051204000508.

121. Moore KT, Plotnikov AN, Thyssen A, Vaccaro N, Ariyawansa J, Burton PB. Effect of multiple doses of omeprazole on the pharmacokinetics, pharmacodynamics, and safety of a single dose of rivaroxaban. J Cardiovasc Pharmacol. 2011;58(6):581-8. https ://doi.org/10.1097/FJC.0b013e31822f6c2b.

122. U.S. Food and Drug Administration. Rivaroxaban: clinical pharmacology and biopharmaceutics review; 2010. https://www.acces sdata.fda.gov/drugsatfda_docs/nda/2011/022406Orig1s000ClinP harmR.pdf. Accessed 29 Jan 2020. 